\title{
Implementações no Design do Jogo Going Abroad: descrição de sistemas e avaliação inicial do protótipo
}

Susana Cristina dos Reis - UFSM/DLEM - susana.reis@ufsm.br Quélvin Siqueira Gazen - UFSM/PIBIC- quelvinsgazen@gmail.com Renan de Siqueira Cecchin - UFSM/PROBIC - renancecchin07@gmail.com

\section{Resumo}

Este artigo reporta o desenvolvimento de um jogo digital educacional, cujo processo de design envolveu uma pesquisa exploratória que fomentou a criação de um novo produto tecnológico. Going Abroad (GA) caracteriza-se como um jogo sério (crítico) e tem caráter inovador porque oferece uma proposta de jogo para o ensino de língua inglesa de modo lúdico, que não se detém no ensino de conteúdos específicos (tais como vocabulário descontextualizado ou sentenças isoladas), mas que inclui em seu design a possibilidade de construção narrativa por meio de um sistema de escolhas. Esse sistema se propõe a favorecer o uso da linguagem pelos jogadores, buscando desse modo cativar e inserir o aluno-jogador em contextos que podem propiciar a diversão, o engajamento e a aprendizagem. Aliamos à proposta de narrativa não linear os desafios, com o objetivo de chamar a atenção do jogador à resolução dos problemas. As implementações feitas na versão Demo, até o presente momento, refletem as etapas de desenvolvimento que são orientadas por pressupostos teóricos multidisciplinares, o que nos permitiu elaborar quatro sistemas fundamentais no jogo, os quais são: diálogo, inventário, navegação e espírito.

Palavras-chave: Going Abroad; Design; Sistemas; Avaliação; Versão Demo do jogo GA.

Design implementations in the game Going Abroad: a description of systems and an initial evaluation of the prototype

\section{Abstract}

This paper reports the development of a digital educational game of which the designing process involved an exploratory research that promoted the creation of a new technological product. Going Abroad can be characterized as serious (critical) game and has an innovative character because it offers a playful way of teaching the English language, not centered around specific content (such as decontextualized vocabulary or isolated sentences), but including in its design the possibility of building the narrative through a system of choices. This system favors the use of language by the players, seeking to captivate and insert the student-player in the contexts which can propitiate fun, engagement, and learning. Challenges fill the non-linear narrative with the objective of holding the player's attention in the resolution of problems. The implementations made in the Demo version to this moment reflect the stages of development which are oriented by a multidisciplinary literature, allowing us to elaborate the four fundamental systems in the game, which are: dialogue, inventory, navigation and spirit.

Keywords: Going Abroad; Design; Systems; Evaluation; Demo Version of the game GA. 


\section{Introdução e princípios fundamentais para o design de jogos sérios}

O Design de Jogos tem sido foco de investigação de pesquisa de diversas áreas disciplinares e desse modo tem fomentado também a produção de jogos ${ }^{1}$ sérios para possibilitar práticas inovadoras de ensino por meio de tecnologias em sala de aula.

De acordo com McGonical (2012), todo o jogo caracteriza-se por ter metas, regras, sistema de feedback e possibilitar a participação voluntária do jogador no ato de jogar. Para a autora, as regras são responsáveis por focar, fixar a atenção e orientar os participantes a atingir a meta e a obter diferentes resultados durante o jogar. Já as regras que, por um lado, limitam as ações dos participantes, por outro lado liberam a criatividade e estimulam o pensamento estratégico.

Ainda, em um jogo, a autora salienta que o sistema de feedback é essencial para promover a motivação dos jogadores. Por isso, o feedback tem papel importante em fornecer informações sobre a movimentação dos seus participantes em direção à meta, seja este dado em forma de pontos, níveis, placar, barras de progresso ou outros meios. Para McGonical (2012), a característica participação voluntária consiste em o jogador aceitar de forma consciente e voluntária a meta, as regras e o feedback oferecido pelo sistema do jogo. Por isso, a participação voluntária indica que o jogador tem a liberdade de escolha, assim como pode aceitar de forma consciente e voluntária o ato de jogar, estabelecendo parâmetros seguros e prazerosos para executar as atividades em que se envolve.

Para McGonical (2012), esses critérios são essenciais e definem qualquer bom jogo, portanto, ao elaborar o seu design é imprescindível atentar para tais características, já que têm a real intenção de engajar o jogador e, a partir disso, gerar a diversão, a motivação, e, também, a aprendizagem.

Na concepção de Huizinga (2000), jogos são entendidos como:

É uma atividade ou ocupação voluntária, exercida dentro de certos e determinados limites de tempo e de espaço, segundo regras livremente consentidas, mas absolutamente obrigatórias, dotado de um fim em si mesmo, acompanhado de um sentimento de tensão e de alegria e de uma consciência de ser diferente da "vida quotidiana" (HUIZINGA, 2000, p. 24, grifos do autor).

Entre as definições supracitadas, o que chama nossa atenção ao analisá-las é que a definição de Huizinga (2000) em comparação com a de McGonigal (2012) apresenta também as palavras atividades ou ocupação voluntária, regras, bem como permite a inferência da ideia de meta, juntamente com o sentimento de satisfação, alegria, tensão que tal atividade pode proporcionar ao jogar.

Considerando tais definições, ao navegar e avaliar jogos educacionais de língua inglesa, disponíveis gratuitamente na Internet, como grupo de pesquisa temos percebido que nem sempre os educacionais (ou sérios) geram tais sentimentos em seus usuários, e, ao contrário, muitas vezes, são referenciados pelos jogadores como sendo chatos. Com isso, concluímos que esses jogos não trazem em seu design recursos que podem gerar a motivação e o engajamento do aluno. Em vista disso, temos nos questionado: o que há em um jogo comercial que o torna tão atrativo para seus jogadores e que não encontramos em um educacional?

\footnotetext{
${ }^{1}$ Para Ulisack (2010), jogos sérios são jogos digitais (de edutainment ou de simulações), com a intenção de ensinar conteúdos específicos e/ou praticar habilidades/competências.
} 
Gee (2005) ressalta que todos os bons jogos têm princípios de aprendizagem e o que os tornam tão atrativos são a imersão e a interação proporcionadas pelos cenários/contextos em que os alunos-jogadores se inserem, além da possibilidade de engajamento e produção, dando a eles a agência na resolução dos desafios apresentados, bem como a possibilidade de escolha quanto à resolução de problemas/desafios. Ao inserir-se em um jogo, o aluno pode customizá-lo, correr riscos, explorar, desenvolver pensamento estratégico e viver a performance mesmo antes de se ter competência.

A possibilidade de vivenciar todos esses princípios, pode gerar ainda os sentimentos de prazer ou de frustração ou, inclusive, frustração prazerosa, e, mesmo assim instigar o desejo de continuar a jogar. Esses princípios, entre outros, nos desafiam a pensar: por que isso acontece? O que há de tão atrativo em jogos que os tornam espaços tão atrativos e desafiadores?

Neste artigo, não temos ainda dados que nos permitem concluir quais são as reais razões/motivos para isso, porém nossas experiências prévias e, tentativas com design de jogos educacionais, têm nos ensinado que os comerciais, além de serem desenvolvidos com o propósito de atender às tendências comerciais, trazem narrativas cativantes, que favorecem a imersão do jogador, levando-o agir como protagonista da narrativa, a resolver problemas que exigem tomadas de decisões e os conduzem a outros desafios mais complexos. Desse modo, oportunizam ao jogador a obtenção de recompensas que o motivam e favorecem o desenvolvimento de sua performance durante o ato de jogar.

$\mathrm{Na}$ área de Linguagens, entendemos que as escolhas léxico-gramaticais de um texto, sejam elas verbais ou não verbais, influenciam diretamente na sua compreensão, ou seja, no nosso caso, entendemos o jogo como um hipergênero (Reis, 2017) e, também, como um texto multimodal, cujas escolhas inseridas em seu design podem influenciar na maneira como o jogador age durante o ato de jogar, consequentemente, nas escolhas e na constituição da narrativa (Reis, 2019, em comunicação oral ${ }^{2}$ ).

Em publicações anteriores feitas pela equipe (Gazen; Reis; Gomes, 2019) exploramos a criação de jogos digitais voltados para o ensino de língua inglesa e suas adaptações dentro da plataforma para uso em um computador pessoal. As contribuições discutidas em tais estudos continuam a nortear os esforços relativos ao processo e a produção do Going Abroad (GA). Porém, o interesse em desenvolver uma versão mobile, traz a necessidade de maior aprofundamento teórico quanto ao uso de aplicativos móveis na educação, bem como um estudo mais aprofundado da modalidade ubíqua.

Tendo em mente esses pressupostos, outra inquietação que surge é: como inserir todos esses aspectos e princípios em um jogo sério (educacional)? como desenvolver um que potencialmente ensine conteúdos (a língua inglesa), mas que também divirta, engage e motive nossos alunos? Na tentativa de implementar no design de um jogo educacional tais elementos, que recorrentemente encontramos nos comerciais, por meio desta pesquisa apresentamos uma proposta de um serious game para o ensino de língua inglesa que tenha metas, regras e sistema de feedback, e, principalmente, motive o aluno a jogar.

Para isso, neste artigo, na sequência, apresentamos os procedimentos metodológicos planejado para implementar os sistemas encontrados na versão Demo do Going Abroad e apresentá-lo como uma alternativa para fomentar o ensino de língua inglesa de modo lúdico. Para reportar como se deu o processo de desenvolvimento desse jogo, descrevemos na metodologia as diferentes etapas e, na seção de resultados e discussão, discutimos quatro sistemas implementados, e as demais mecânicas e elementos de design elaborado para o GA.

\footnotetext{
${ }^{2}$ Em agosto de 2019, sessão de orientação, registro em relatório técnico de atividades de bolsista. V. $18 \mathrm{~N}^{\mathrm{o}} 1$, julho, 2020 DOI: 


\section{Procedimentos Metodológicos para elaborar o Design do Jogo GA}

Esta pesquisa é desenvolvida dentro do projeto Análise e Produção de Aplicativos e Jogos Digitais Educacionais Interdisciplinares para o ensino de línguas na Universidade, na Universidade Federal de Santa Maria (UFSM), em cujo projeto adotamos as características de uma pesquisa exploratória, a qual parte da análise de pressupostos teóricos interdisciplinares para orientar o desenvolvimento de um produto tecnológico. A abordagem de análise de dados coletados é qualitativa e configura-se como um estudo de caso, por focalizar o desenvolvimento de um jogo ou produto tecnológico em específico.

Para isso, a investigação iniciou-se coletando publicações acadêmicas no formato de artigos sobre o uso e o desenvolvimento de jogos educacionais, a fim de identificar pressupostos teóricos que auxiliassem no desenvolvimento de jogos interdisciplinares, como propomos no projeto do GA. Durante a fase inicial da pesquisa exploratória, selecionamos e, também, avaliamos aplicativos e jogos gratuitos (todos para plataformas mobile), envolvendo a investigação de possibilidades de uso para o ensino de Língua Inglesa (LI). A descrição dos games analisados e selecionados, bem como a avaliação feita sobre esses aplicativos será apresentada na seção de análise de dados.

Para auxiliar nesse processo, foram realizadas concomitantemente as leituras de trabalhos na área de avaliação e aplicação de jogos educacionais, procurando aliar interações/mecânicas emergentes à teoria com vistas a implementar melhorias no GA, respeitando as etapas previstas no projeto e fazendo adaptações na narrativa para suprir mudanças necessárias à portabilidade do game para dispositivos mobile.

As etapas para o desenvolvimento do GA foram as seguintes: Etapa 1- análise exploratória e diagnóstica de pressupostos teóricos e de jogos digitais para fomentar o design do novo game a ser desenvolvido; Etapa 2 - planejamento e escrita da narrativa neste momento foi feito o planejamento do mapa e se iniciou a construção dos cenários, desafios e diálogos que compõem a narrativa; Etapa 3 - Design inicial de interface modelagem inicial dos cenários, avatares e objetos; escolha de assets; definição de estilo do jogo, menu, layout, cores, etc. Etapa 4 - Elaboração/Criação de sistemas essenciais no GA; Etapa 5 - Implementação e ajustes na interface e na narrativa; Etapa 6 - Avaliação e testagem da versão demo; Etapa 7 - Avaliação por usuários potenciais; Etapa 8 $\operatorname{Re}($ design).

$\mathrm{Na}$ equipe de desenvolvimento envolveram-se, até o presente momento, a professora coordenadora do projeto, dois bolsistas de iniciação científica, um da área de Letras (PIBIC) e uma da área da Ciência da Computação (PROBIC) e mais 4 voluntários, nas atividades do projeto. Os participantes voluntários são três da área da Ciência da Computação e um aluno do Ensino Médio. O envolvimento desses participantes na equipe foi essencial para avançar na modelagem e prototipagem da versão demo, bem como auxiliar na elaboração dos sistemas e contribuir no compartilhamento e troca de ideias quanto ao design do GA, já que todos os membros também são jogadores e trazem para o trabalho em equipe suas experiências e expectativas sobre o que esperam encontrar em um Jogo educacional para que este seja engajante e motivador.

Para avaliar a versão Demo do GA, utilizamos os pressupostos teóricos do framework MEEGA+ (Petri; Gresse von Wangenheim; Borgatto, 2019), cujas categorias buscam evidenciar, as categorias do ARCS (Atenção, Relevância, Confiança e Satisfação), ou seja, buscamos avaliar em que medida o $G A$ cativa a atenção, torna-se 
relevante, desperta a confiança e gera satisfação durante o ato de jogar. Com base nesses critérios, o protótipo foi avaliado por quatro participantes, como um estudo inicial piloto.

\section{Pesquisa exploratória e análise diagnóstica de jogos digitais para dispositivos móveis}

\subsection{Avaliação MEEGA+ de jogos mobile}

Quatro jogos para dispositivos móveis foram selecionados para análise nesta fase inicial da pesquisa. Os critérios para escolha foram: a presença de textos em língua inglesa; a gratuidade; a existência de versão/versões mobile; requisitos de sistema: Android 4.0 ou acima e memória RAM entre 1GB e 2GB. A partir desses critérios, avaliamos os selecionados, levando em consideração o framework de avaliação MEEGA+ (Petri; Gresse von Wangenheim; Borgatto, 2019).

Tendo em vista identificar se as percepções de outros jogadores com relação aos jogos selecionados inicialmente pela equipe de desenvolvimento, convidamos seis alunos-jogadores para responderem a um questionário avaliativo (composto de 31 perguntas), tendo por base suas experiências, porém apenas obtivemos a resposta de quatro.

Nesse momento, aplicamos a metodologia MEEGA+ e os testadores respeitaram as designações: Discordo totalmente (DT), Discordo em parte (DP), Nem Concordo nem Discordo (NCND), Concordo em parte (CP) e Concordo totalmente (CT) para avaliar os jogos dentro das categorias usabilidade, confiança e satisfação, interação social, diversão, atenção focada e relevância. Vale ressaltar que interessava a nossa equipe identificar aqueles com um gameplay potencialmente engajante para jogadores veteranos e iniciantes, evitando alto nível de dificuldade para aprender a jogar e prevalecendo gráficos com alta definição para que fossem suportadas a percepção de qualidade e a vontade do jogador de explorá-lo. A seguir, apresentamos uma breve descrição de cada jogo somada às avaliações dos testadores.

Void Tyrant '́ é um jogo gratuito para Android, que explora a temática da exploração espacial. É do gênero roguelike, em que o jogador volta do começo do game ao morrer, sempre com desafios e recompensas randomizados. Para isso, a experiência do jogador é considerada em tentativas subsequentes de conquistar a vitória, o que traz novas possibilidades após cada falha. No seu design, elementos de estratégia e aventura são combinados por meio da jogabilidade de um card game somado a um enredo de ficção científica. Por meio da avaliação dos testadores, é possível afirmar que seus pontos fortes são: a progressão dos desafios (a qual é boa no sentido em que se aplicam gradualmente os incrementos de dificuldade); design atraente (baseado em gráficos e esquemas de cores bem trabalhados) e; relativa facilidade de se aprender a jogar. $\mathrm{Na}$ opinião dos avaliadores, Void Tyrant ainda valoriza o esforço pessoal por ser "um RPG mobile que não foca inteiramente em microtransações ou que não desafia o jogador ao tentar desenvolver um jogo que atenda todos (...)" (P\#3), e apresenta os seguintes pontos fracos: baixo nível de personalização do protagonista e eventual monotonia (que surge pela repetição de tarefas do jogo): Na opinião de P\#2 “após jogar por uma hora senti que o jogo parava de oferecer mais conteúdos para o jogador, tornando a jogabilidade um pouco massante com o tempo".

\footnotetext{
${ }^{3}$ Disponível em: https://play.google.com/store/apps/details?id=com.armorgames.voidtyrant\&hl=pt_BR

${ }^{4}$ Esse gênero é principalmente caracterizado por fases de estrutura aleatória e morte permanente (i.e. o jogo recomeça toda vez que a saúde do jogador chega a zero).

V. $18 \mathrm{~N}^{\mathrm{o}} 1$, julho, 2020 RENOTE

DOI:
} 
Brawl stars ${ }^{5}$ é um jogo de luta em equipes do gênero MOBA ${ }^{6}$, no qual os jogadores se enfrentam para ganhar gemas e tornar seus campeões os mais fortes, abordando as temáticas de ficção científica e fantasia. As avaliações dos testadores apontam que este tem uma parte visual consistente atrativa durante o gameplay "É um jogo bem consistente, colorido e divertido, com certeza eu jogaria por mais tempo" (P\#2). No quesito múltiplos jogadores, a avaliação foi dividida: "Brawl Stars é divertido e cheio de ação em suas partidas multiplayer. Os variados modos impedem que o gameplay caia na monotonia" (P\#4); Já para o P\#1 "O campo de batalha multijogador é meio confuso e fora de controle." Ademais, Brawl Stars foi considerado fácil de aprender, porém pouco cativante em geral.

Hearthstone é um jogo do gênero estratégia para múltiplos jogadores online, baseado em cartas de heróis e monstros, cuja temática de fantasia explora magia e efeitos especiais usados para conquistar a vitória contra um herói inimigo. Hearthstone também teve sua parte gráfica bem avaliada e sua progressão de desafios mostrou capacidade de gerar engajamento "graças ao seu alto valor de produção e sua progressão bem trabalhada, Hearthstone me prendeu e manteve o senso de novidade vivo por muitas horas." (P\#4). Porém, dois testadores consideraram que a constante necessidade de atualização de estratégias foi um detrimento do gameplay "conforme novas atualizações são lançadas, o jogador é obrigado a atualizar todas as suas estratégias e cada vez mais ter que conhecer todas as cartas, isso torna o jogo um pouco frustrante após um tempo" (P\#2); Na opinião do P\#3, “caso você almeja avançar, é necessário investir em decks de cartas compradas pela loja online/sistema de microtransações.".

Cooking Madness é um jogo de simulação de cozinha em que cada fase se apresenta como uma missão de servir clientes, com receitas novas sendo adicionadas à medida que o jogador avança. Os avaliadores apontaram que o jogo apresenta um baixo nível de dificuldade, um design visual e um começo atrativos. Apesar disso, foram criticadas falhas na construção dos desafios e apontada a ausência de modos multiplayer: "Eu acredito que poderiam ser propostos desafios mais elaborados e diversos para não deixar o jogador se desmotivar ou, até mesmo, achar que não há nada de novo no jogo" (P\#3) e "Cooking Madness é dinâmico e divertido em single player, mas se beneficiaria muito com o modo multiplayer presente em outros jogos de temática parecida (como Overcooked 1 e 2)" (P\#4).

A partir das análises, é possível concluir que, no design e na avaliação de jogos, usuários tendem a considerar como elementos essenciais: apresentação de gráficos e de paleta de cores consistentes e bem produzidos; progressão dos desafios bem organizada, sem mudanças drásticas (picos) de dificuldade; mecânicas bem explicadas; e desafios que recompensam o jogador de acordo com seu esforço. Essas são as principais características observadas e que, também, consideramos responsáveis por fazer um game ser bem avaliado. Tais aspectos representam, ainda, o que pretendemos aplicar e implementar nos sistemas do jogo GA.

\subsection{Descrição dos sistemas do Jogo GA}

O GA está sendo desenvolvido na plataforma Unity, tendo em vista sua compatibilidade com diversos dispositivos e praticidade. Para modelar os cenários e os

\footnotetext{
${ }^{5}$ Disponível em: https://play.google.com/store/apps/details?id=com.supercell.brawlstars\&hl=pt_BR

${ }^{6}$ Multiplayer Online Battle Arena, gênero popularizado por jogos como DOTA 2 (VALVE, 2013) e League of Legends (RIOT GAMES, 2009).

${ }^{7}$ Disponível em: https://play.google.com/store/apps/details?id=com.blizzard.wtcg.hearthstone\&hl=pt_BR V. $18 \mathrm{~N}^{\mathrm{o}} 1$, julho, 2020 DOI: RENOTE
} 
avatares, compramos um pacote de Assets, na loja da Unity, chamado POLYGON- City $P a c k$, que inclui vários objetos perfeitos para tornar o cenário mais amigável ao jogador, adotando um estilo Low Poly.

O GA caracteriza-se como um jogo sério e tem como objetivo ensinar Inglês de forma mais lúdica, fazendo uso de missões e desafios linguísticos que precisam ser lidos e compreendidos para avançar na narrativa. A história gira em torno de um contexto similar ao de um intercâmbio com elementos de ficção científica ( $s c i$-fi) e foi planejada com o intuito de inserir o aluno em situações de uso da língua em um ambiente completamente em Inglês.

A narrativa coloca o jogador no papel de um estudante, que assume a identidade de um assistente de pesquisa, que viaja ao Canadá para resolver problemas linguísticos causados por dificuldades de comunicação com seres de outra dimensão recém-chegados à Terra. A introdução de elementos sci-fi veio da necessidade de tornar a história menos monótona e trazer um tom de mistério para incentivar a exploração e o engajamento do jogador na resolução dos desafios apresentados no jogo.

A concepção de linguagem que subjaz o GA é que o usuário aprende a língua pelo uso, bem como pela imersão e resolução dos desafios. Em vista disso, buscamos apresentar, ao longo do jogo, vários desafios que o jogador deverá solucionar, a partir da sua leitura e compreensão, ao fazer escolhas que indicam o uso mais apropriado da linguagem para a interação prevista.

Além disso, o aluno poderá fazer associações entre representações verbais e não-verbais, que são apresentadas de modo contextualizado dentro da narrativa proposta. $\mathrm{O}$ contato e resolução dos desafios permitem que o aluno desenvolva a sua agência, principalmente tendo total controle sobre as suas ações e isso ainda o possibilita que tome decisões sobre os problemas, ao interagir com outros avatares e/ou com outros objetos encontrados nos diferentes cenários do jogo.

O GA inicia com uma cutscene, que busca apresentar e inserir o aluno no universo do game, o qual simula um contexto de uma cidade universitária em um país estrangeiro. A cutscene apresenta brevemente o mapa e, após seu término, direciona o jogador para o primeiro diálogo com um personagem. Nessa conversa, é necessário ficar atento ao conteúdo do texto para responder, já que o medidor de espírito será afetado pelas escolhas e interpretará as intenções do jogador. Após isso, o desafio posterior será explicado ainda nessa interação.

Por meio dos diálogos, pretendemos ensinar novas expressões idiomáticas ao aluno e possibilitar que ele aprenda a língua-alvo pela interação, fazendo associações entre língua e contexto, ao inserir-se em diferentes situações comunicativas e gêneros que serão apresentados durante o gameplay. Nos diálogos, as expressões que julgamos importantes para a aprendizagem são destacadas em cor amarela, com a intenção de chamar a atenção do jogador. Caso o aluno não as compreenda, suas dúvidas podem ser esclarecidas com a assistência de uma $N P C$ (personagem não-jogável), que estará à disposição ao longo da história para esclarecer dúvidas linguísticas e dar suporte, sempre que necessário.

\subsubsection{Sistema de Navegação}

O sistema de navegação foi criado tendo base em um pacote disponibilizado gratuitamente pelo Unity, especificamente o script ThirdPersonController. Esse script foi usado em conjunto com os agentes de navegação oferecidos pelo programa. Por isso, criamos um modo de movimentação via clique do mouse (versão para PC) ou toque na V. $18 \mathrm{~N}^{\circ} 1$, julho, 2020 RENOTE

DOI: 
tela (versão mobile). Os cliques registrados estão localizados em objetos de uma camada específica que a Unity reconhece como superfície para o jogador (i.e. paredes, chão, etc). A Figura 1 ilustra esse aspecto do jogo.

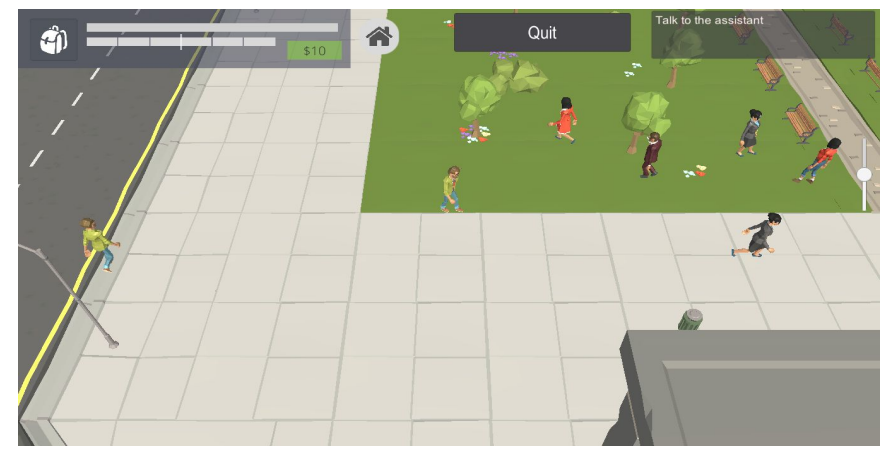

Figura 1 - Sistema de navegação.

\subsubsection{Sistema de Diálogo}

O sistema de diálogo foi criado para suportar qualquer tipo de diálogo, sustentando elementos como: transição de câmeras, textos coloridos, mudanças de acordo com escolhas e entregas de itens. Para implementar os diálogos, criamos um gerenciador que cuida de escrever o texto da fala, mostrar o botão da próxima alternativa e o nome do $N P C$, enquanto isso os diálogos são preenchidos pelo editor do Unity, de acordo com a fala prevista para cada personagem.

Ao se aproximar de um $N P C$, o jogador verá o botão de fala, que é mostrado na parte inferior da tela. Após o clique no botão, a câmera se aproxima do personagem e as mensagens são mostradas em uma caixa de texto, como ilustrado na Figura 2.

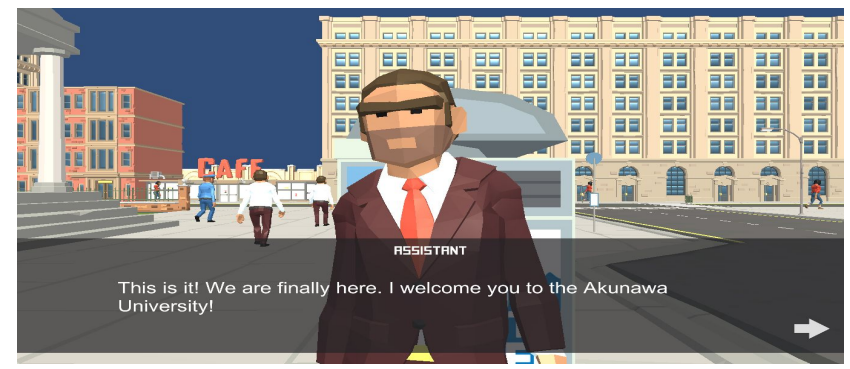

Figura 2 - Sistema de diálogo.

Ao clicar nos textos coloridos, o jogador liga para um personagem para descobrir o significado da palavra, como ilustrado na Figura 3. Se essa palavra estiver registrada, o jogador recebe uma resposta explicando o significado; caso contrário, a chamada não é atendida.

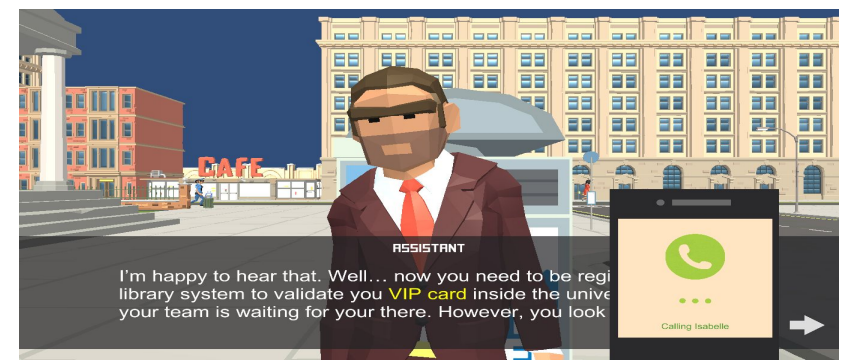

Figura 3 - Jogador pedindo ajuda para uma NPC. 


\subsubsection{Sistema de Inventário}

Para o sistema de inventário, usamos um botão com um ícone de mochila para indicar ao jogador que essa representação é o espaço em que ele guarda os itens que irá coletar e poderá ser acessado por ele quando tiver necessidade. Ao clicar no ícone, uma janela se abre mostrando os vários espaços que armazenam os itens coletados (Figura 4). Se o item for usável, um botão surge para que o item seja consumido.
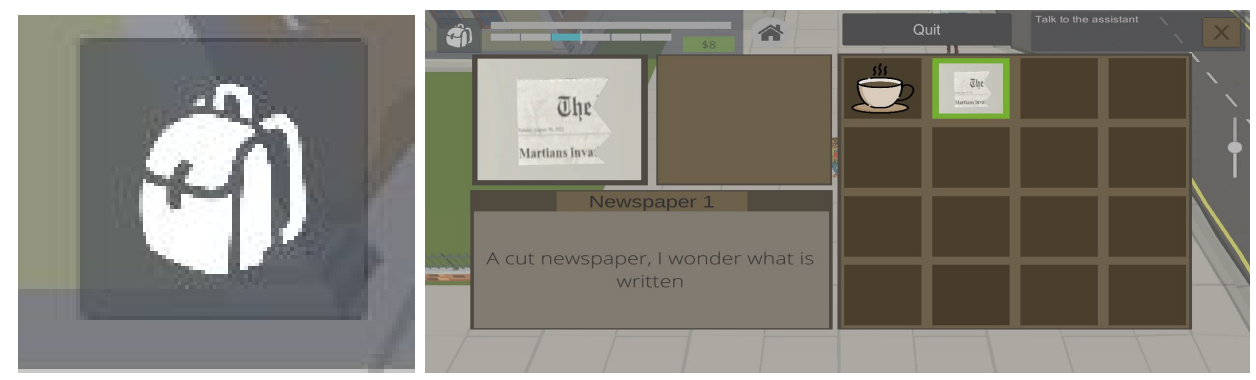

Figura 4 - Inventário com itens.

Ao explorar o mundo do GA, é possível encontrar diferentes itens coletáveis, para adicioná-los ao inventário utilizando o botão de pegar que aparece na tela quando o jogador se aproxima. Ao clicá-lo, o item é adicionado a um espaço vazio do armazenamento. Em lojas em que o jogador pode comprá-los, o sistema funciona de forma semelhante, com a diferença de que os itens são adicionados diretamente ao inventário no ato da compra. A Figura 5 mostra o item Newspaper sendo coletado.

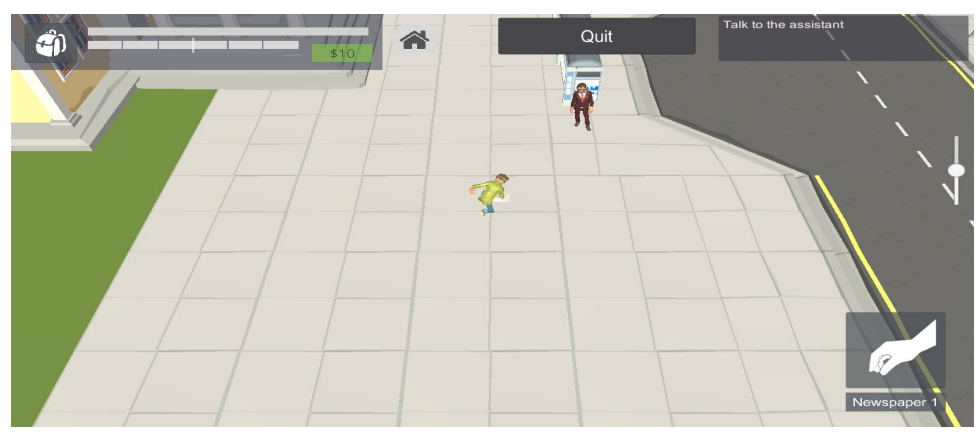

Figura 5 - Jogador pegando item do chão

\subsubsection{Sistema de Espírito e Energia}

O sistema de espírito representa o sistema de energia do jogador e é importante para fazer o com que ele progrida no jogo, pois algumas ações específicas dentro do game podem ter impacto positivo ou negativo. Isso é mostrado em uma barra na parte superior esquerda da tela como uma barra (espírito), que representa as mudanças de humor do personagem principal, as quais são baseadas nas escolhas do jogador. Com o progresso da narrativa, o medidor de espírito irá impactar a relação do protagonista com os outros personagens no jogo. Dessa forma, ele poderá perceber o resultado de suas ações e responder com maior atenção ao enredo.

\subsection{Avaliação da Versão Demo do GA}


Testes preliminares já foram realizados e contemplaram a aplicação do GA com indivíduos do público-alvo (alunos do Ensino Médio e universitários). No entanto, ainda precisamos coletar mais dados para uma avaliação conclusiva, incluindo a sua inserção em contextos formais de ensino.

Os avaliadores da versão Demo perceberam que o nível linguístico do jogo exige que o usuário tenha conhecimentos intermediários em língua inglesa para que compreenda e resolva os desafios. Além desse aspecto, salientou-se que o uso demasiado de textos verbais na fase introdutória pode gerar desmotivação e pouco engajamento. Com isso, no redesign buscaremos reduzir as instruções textuais na fase tutorial e explorar nesse momento mais aspectos não verbais com vista a possibilitar maior engajamento no contexto do jogo.

\section{Considerações Finais}

Esta pesquisa consistiu na coleta e análise de um corpus de jogos desenvolvidos para dispositivos móveis com o intuito de agregar descobertas que podem favorecer e modificar o roteiro em adaptação da versão mobile do GA. Com base nas leituras teóricas e análises dos jogos selecionados para esta pesquisa, planejamos a continuidade e expansão do roteiro do jogo, incluindo mais cenários completos para futuras aplicações em contextos de ensino, a fim de expandir o roteiro com base nas leituras e na análise de aplicativos/jogos mobile.

Alguns sistemas, incluindo o de ajuda, necessitam de polimento e atualizações, visando a melhor funcionalidade possível, assim como a revisão dos textos narrativos, buscando apresentar instruções mais diretas, principalmente na fase tutorial. Também, embora o design Low Poly tenha sido avaliado como um aspecto positivo, temos ainda necessidade de conseguir novos modelos de cenários, objetos e avatares para as próximas fases do jogo. Essas são algumas das melhorias que devem ser implementadas em versões futuras do GA, bem como a conclusão e a apresentação da versão final em junho de 2021.

\section{Referências Bibliográficas}

GAZEN, Q. S.; REIS, S. C.; GOMES, A. F. Going Abroad 2D: o desenvolvimento da narrativa de um jogo sério para o ensino de língua inglesa. In: Revista Tecnologias na Educação. Ano 11, vol. 32. p.1-12, 2019. Disponível em: $<$ https://tecedu.pro.br/wp-content/uploads/2020/02/Art4-Ano-11-vol32-Dezembro-2019. pdf-.pdf>. Acesso em: 20 jan. 2020.

GEE, J. P. Good video games and good learning. In Phi Kappa Phi Forum, v. 85, n. 2, p. 33-37. 2005. Disponível em: $<$ http://jamespaulgee.com/pdfs/Good\%20Games\%20and\%20Good\%20Learning.pdf>. Acesso em: 20 ago. 2018.

HUIZINGA, J. Homo ludens: o jogo como elemento da cultura. 4 ed. São Paulo: Perspectiva, 2000.

MCGONIGAL, J. Realidade em jogo: por que os games nos tornam melhores e como eles podem mudar o mundo. Rio de Janeiro: Best Seller, 2012. 
PETRI, G.; GRESSE VON WANGENHEIM, C.; BORGATTO, A. F. . MEEGA+: Um Modelo para a Avaliação de Jogos Educacionais para o ensino de Computação. Revista Brasileira de Informática na Educação (RBIE), v. 27, p. 52, 2019.

REIS, S. C. Pesquisa e ensino sobre jogos digitais na universidade: em busca de diretrizes para o design e uso de jogos em aulas de língua inglesa. In: TOMITCH, L. M. B.; HEBERLE, V. M. (Org.). 2017. Perspectivas atuais de aprendizagem e ensino de línguas. 1 ed. Florianópolis: PPGI/UFSC, v. 1, p. 15-77, 2017.

REIS, S. C.; GAZEN, Q. S. Going Abroad 3D: um jogo educacional em elaboração para o ensino de língua inglesa. In: CICLO DE PALESTRAS SOBRE NOVAS TECNOLOGIAS NA EDUCAÇÃO, 27, 2019, Porto Alegre. Anais... Porto Alegre: Centro Interdisciplinar Novas Tecnologias na Educação/ Universidade Federal do Rio Grande do Sul, 2019, p. 28-35.

ULICSAK, M.; WRIGHT, M. Games in education: Serious Games. Bristol, Futurelab. 2010. Disponível em: <https://www.nfer.ac.uk/publications/FUTL60/FUTL60.pdf>. Acesso em: 20 ago. 2019. 